\title{
Numerical simulation of shallow square boxes with flanges based on Dynaform
}

\author{
Liu cunping ${ }^{1, a}$, Liu yong ${ }^{1}$ and Guo sheng ${ }^{1}$ \\ ${ }^{1}$ Yibin Vocational and Technical College, Department of Modern manufacturing, 644003 Sichuan Province, China
}

\begin{abstract}
In this work, Numerical simulations based on finite element method have been carried out to study the effect of important process parameters on formability of AA5182 alloy sheets. The blank holder force between $0.5 \mathrm{KN}$ and $3 \mathrm{KN}$ and friction coefficient $(\mu)$ between 0.05 and 0.20 , which resulted in successful drawing, was evaluated. Maximum percentage thinning has always been obtained at the conjunction of corner and bottom. The maximum thinning rate was nearly $20 \%$ for a maximum holder force of $3 \mathrm{KN}$. Friction coefficient simulations are shown that as friction coefficient increasing, the thinning rate becomes larger and low friction coefficient is beneficial to the sheet forming.
\end{abstract}

\section{Introduction}

In recent years the great demand for lightweight metals has increased significantly in manufacturing, especially in automobile industry. Aluminum alloy is one of the most important lightweight metals, which is regarded as one of the most important green automobile materials[12]. It has an attractive combination of characteristics in terms of low density, high mechanical properties, elevated corrosion resistance. But one of the main limitations of aluminum alloy is lower strength and formability when compared to low carbon steel. Generally, in any operation large amount of time is consumed in molds trial and bad research and there are higher chances that the molds were to be redesigned before the desired products were obtained. Because the aluminium alloy forming process is in dependent on large number of parameters, including material properties, tool geometry, machine parameters and working conditions. So, conventional sheet metal forming, research and development involves a lot of expenditure and loss of valuable time. To overcome this problem, computer simulation has been introduced. Finite element analysis for simulating deformation and analyzing the sheet metal forming processes can reduce the experiment time and cut down the production cost.

Much work have been done on the numerical simulation for the aluminium alloy forming. R.P. Garrett studied the forming process and strengthening mechanism of AA6xxx aluminium alloy sheets[3-4]. EI Fakir O studied the solution heat treatment, forming and in-die quenching process of AA5754[5]. Mohamed M S investigated the deformation and failure features of AA6082. Friction plays an important role in the forming of aluminium alloy sheets[6]. Wen-yu MA studied the friction coefficient in deep drawing of AA6111 sheet using finite element method[7]. In this work, the important process parameters namely the blank holder force, lubrication condition and die gap were investigated. Finite element software Dynaform was used in simulating to predict the deformation behavior of the blank sheet.

\section{Finite element simulation}

\subsection{Material properties and model}

In this paper, material used in this study was AA5182 sheet of $1.0 \mathrm{~mm}$ thickness. The mechanical properties of the final processed sheet are given in Table 1. A shallow square boxes with flanges part of $120 \mathrm{~mm}$ side with $15 \mathrm{~mm}$ depth is shown in Figure 1.

Table 1. Mechanical properties of sheets of AA5182 alloy.

\begin{tabular}{|c|c|}
\hline Condition & Parameters \\
\hline Tensile strength(MPa) & 279.6 \\
\hline Yield strength(MPa) & 126.3 \\
\hline Elongation(\%) & 0.24 \\
\hline Strain hardening exponent(MPa) & 310.2 \\
\hline Anisotropy parameter & 0.72 \\
\hline Strength coefficient & 0.60 \\
\hline
\end{tabular}

\footnotetext{
a Corresponding author: liucunping@126.com
} 


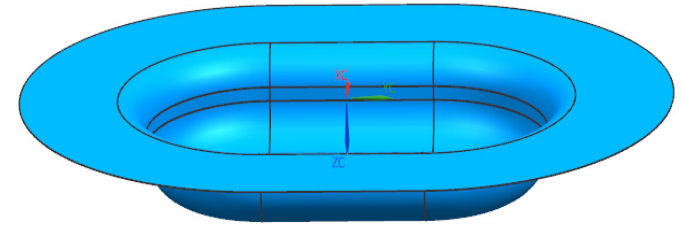

Figure 1. The part of shallow square boxes with flanges.

\subsection{Simulation model}

In this work, the finite element analysis is done using a commercially available software-DYNAFORM. This is a non-linear dynamic simulation package which can simulate and predict different types of sheet metal forming, including stamping, deep drawing, bending, etc. The input models like punch, die and blank holder were constructed in UG software. After the tools were introduced into Dynaform, fine meshing with an element size of $3 \mathrm{~mm}$ is done on the surface of the tool components and on the blank and the nodes are created. In the simulation, tools were modeled as rigid bodies. Barlat material models[8] were used to model the yielding behavior of AA5182 alloy sheet. And the finite elment model for simulation of the parts is shown in Figure 2.

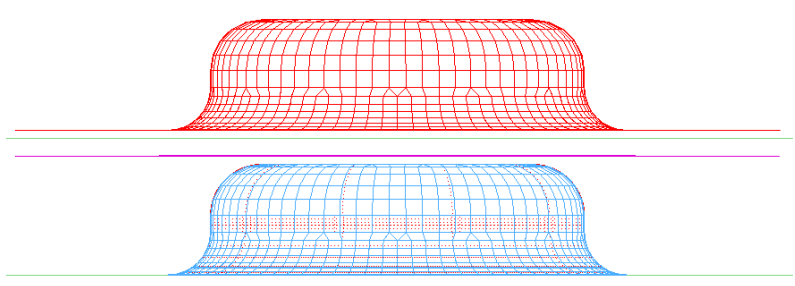

Figure 2. Finite element model for simulation.

\section{Results and discussion}

\subsection{Effect of blank holder force}

The value of blank holder force directly affects the quality of the drawing. If it is too large, the friction increases; too small, the sheet is prone to tear defects. To qualify AA5182 alloy for industrial applications it is important to quantify the ability to control blank binder force by finding the best variable range of binder force. The blank holder force $\mathrm{F}$ can be roughly calculated according to the following formula.

$$
F=A p
$$

Where, A-the total projected area of the sheet; $\mathrm{p}$-unit pressure $(\mathrm{MPa})$ on sheet edge, which value is $1.2 \mathrm{MPa}$ to $1.8 \mathrm{MPa}$.
Based on this formula calculation, $1 \mathrm{KN}$ is set as the initial value of binder force. Then, the binder force were optimized according to the simulation results, until the best value of binder force was obtained. Figure 3 shows that the fracture prediction of drawing with the blank holder force of $3.1 \mathrm{KN}$. Figure 4 and Figure 5 show the forming limit drawing and thickness of AA5182 material with $1 \mathrm{KN}$ blank holder force. We find that the conjunction of corner and bottom is the most serious thinning region. The smallest thickness is $0.867 \mathrm{~mm}$ and the max thinning rate is $13.3 \%$. The external edge of parts is the most serious thickening region. The biggest thickness is $1.058 \mathrm{~mm}$, and the thickening rate is $5.8 \%$. According experience, thinning rate under $25 \%$ and thicken rate under $5 \%$ are safe and feasible[9].

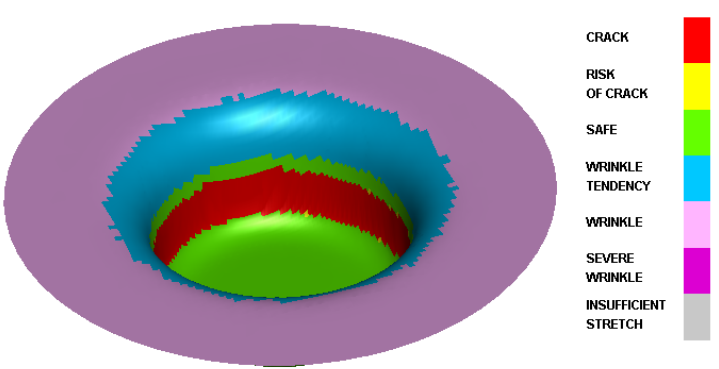

Figure 3. The fracture prediction of $3.1 \mathrm{KN}$ blank holder force.
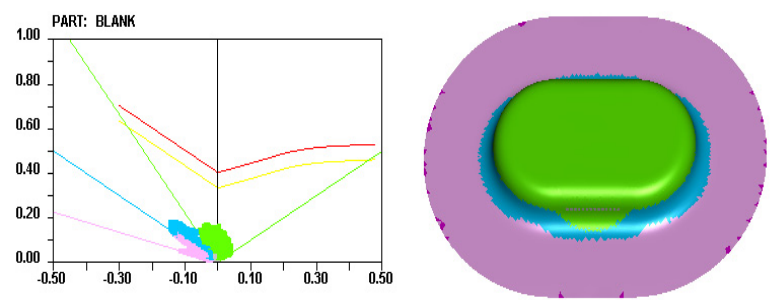

Figure 4. The forming limit drawing of $1 \mathrm{KN}$ blank holder force.
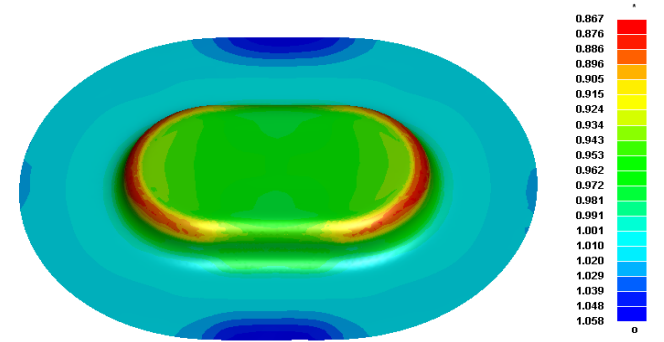

Figure 5. The thickness simulation results of $1 \mathrm{KN}$ blank holder force.

The effect of holder force has been investigated by finite element simulation, which resulted in successful drawing. The smaller holder force, the more prone to crinkling and with the force increasing, rupture occurring. Simulations were done by varying the force between $0.5 \mathrm{KN}$ to $3 \mathrm{KN}$. In successfully formed parts, maximum percentage thinning has always been obtained at the conjunction of corner and bottom. As the holder force was increased, more deformation occurred in the bottom corners in the final stage and the strains in this region 
also increased. So, thinning also increased and maximum percent thinning rate in the part increased to nearly $20 \%$ for a maximum holder force of $3 \mathrm{KN}$ (see Figure 6).

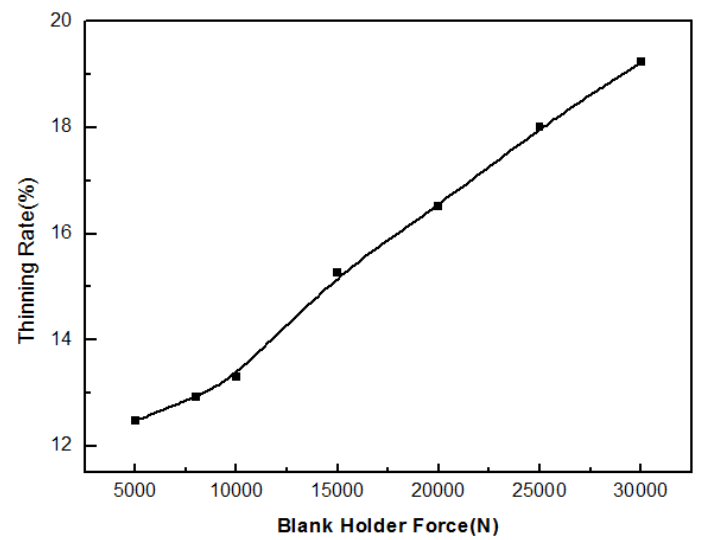

Figure 6. The relation graph between thinning rate and blank holder force.

\subsection{Effect of friction coefficient}

The effect of friction in forming has been investigated by finite element simulation for a holder force of $1 \mathrm{KN}$ which resulted in successful drawing. Simulations were done by varying the coefficient of friction between $\mu=0.05$ to $\mu=0.20$. The predicted thinning from finite element simulation of sheet forming for the highest and lowest cases of fiction coefficient $(\mu=0.05$ and $\mu=0.20)$ are shown in Figure 7. Thickness distribution shows a maximum thinning rate $(14.3 \%)$, for highest friction coefficient $(\mu=0.20)$. With reference to Figure 7 we can see that as friction coefficient increasing, the thinning rate becomes larger, and the shallow square boxes with flanges part is easier to rupture. According above stated, the friction coefficient between die and blank should be controlled at the lower limit value, which is more beneficial to the forming.

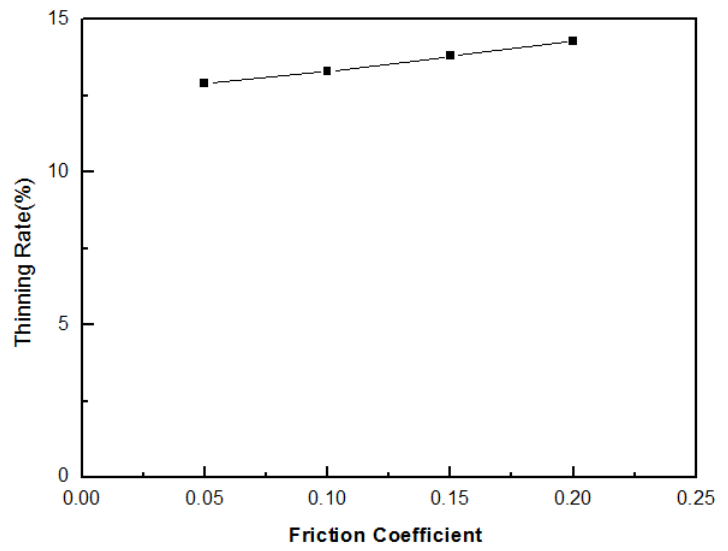

Figure 7. The relation graph between thinning rate and friction coefficient.

\subsection{Effect of die structure}

\subsubsection{Die gap between concave and convex}

With other conditions unchanged, the effect of die gap in forming has been investigated by finite element simulation also. The predicted thinning from finite element simulation of sheet forming for the highest and lowest cases of die gap $(0.50 \mathrm{t}$ and $0.80 \mathrm{t})$ are shown in Table 2. The thinning rate results indicate that the die gap has little effect on the final forming, when the die gap takes between $0.5 \mathrm{t}$ and $0.8 \mathrm{t}$ and $\mathrm{t}$ is the thickness of sheet.

Table 2. The effect of die gap on thinning rate.

\begin{tabular}{|c|c|}
\hline $\begin{array}{c}\text { Die } \\
\text { gap(mm) }\end{array}$ & $\begin{array}{c}\text { Thinning } \\
\text { rate(\%) }\end{array}$ \\
\hline $0.5 \mathrm{t}$ & 13.3 \\
\hline $0.6 \mathrm{t}$ & 13.3 \\
\hline $0.7 \mathrm{t}$ & 13.3 \\
\hline $0.8 \mathrm{t}$ & 13.3 \\
\hline
\end{tabular}

\subsubsection{Radius of the round corner for concave- convex die}

According to deformation characteristics, the convexconcave die takes an main role in controlling flow of metal materials from pressure border region to sidewall region. In this work, the radius of the round corner of concave-convex die was investigated. Result of study indicated that the radius of concave-convex die had an important influence on the thinning rate.

Figure 8 shows the relation graph between thinning rate and radius of concave. It can be observed from the graphs that as the radius of concave increases, there is a decrease before the value of radius reaches the point. But when the value of radius is higher than the point, the thinning rate of the part increases slowly.

Figure 9 shows the relation graph between thinning rate and radius of convex. With the radius of convex increases, the declining trend of thinning rate was obvious.

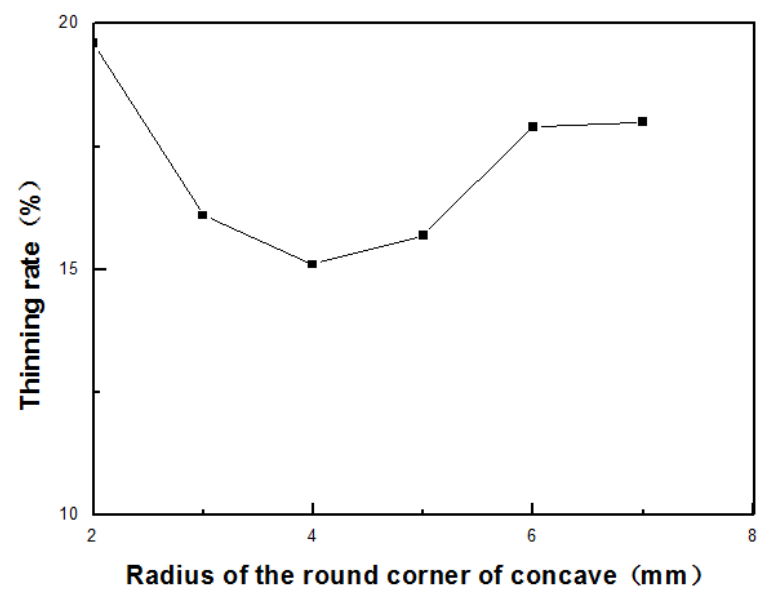

Figure 8. The relation graph between thinning rate and concave radius. 


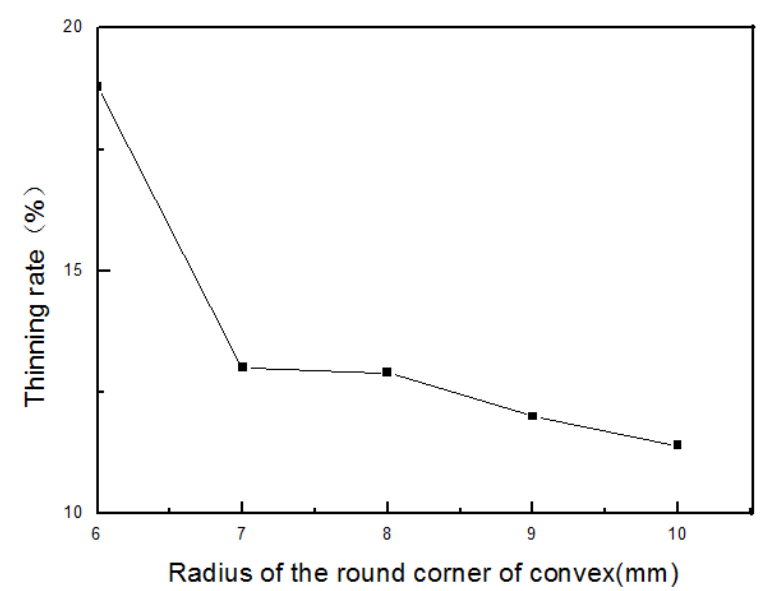

Figure 9. The relation graph between thinning rate and convex radius.

\section{Conclusion}

In this work, formability of AA5182 Al alloy sheets has been investigated by finite element simulation. A process with optimum blank holder force has been indentified to form the shallow square boxes with flanges part. Minimum percentage thinning reduced with increase in coefficient of frication from nearly $12.9 \%(0.05)$ to $14.3 \%(0.20)$. Experimental results also showed that die gap between $0.5 \mathrm{t}$ and $0.8 \mathrm{t}$ has little effect on the final forming. Meanwhile, the Radius of round corner for concave-convex die takes an important role in the part forming process.

\section{References}

1. R. Bhattacharya, M. Stanton, I. Dargue, G. Willianms, R. Aylmore, INT J MATER FORM 3, 267 (2010)

2. F. Djavanroodi, A. Derogar, MATER DESIGN 31,4866(2010)

3. R.P. Garrett, J. Lin, T.A. Dean, Advanced Materials Research 6,673 (2005)

4. R. P. Garrett, J. Lin, T. A. Dean, INT J PLASTICITY 21,1640(2005)

5. OE Fakir, L Wang, D Balint, JP Dear, J Lin, TA Dean, INT J MACH TOOL MANU 87, 39 (2014)

6. M.S. Mohamed, A.D. Foster, J. Lin, D.D. Balint,T.A. Dean, INT J MACH TOOL MANU 53, 27(2012)

7. Wen-yu MA, Bao-yu WANG, Lei FU, Jing ZHOU, Ming-dong HUANG, T NONFERR METAL SOC 25, 2342(2015)

8. F. Barlat, K. Lian, INT J PLASTICITY 5,51(1989)

9. Wang Yun, Yu jin, Small and Special Electrical Machines 7, 62(2009) 